\title{
Assessment of the calibration performance of Meteosat-8/9 and MTSAT-1R visible channels using cloud targets (Withdrawal Notice)
}

Byung-Ju Sohn, Seung-Hee Ham

Byung-Ju Sohn, Seung-Hee Ham, "Assessment of the calibration performance of Meteosat-8/9 and MTSAT-1R visible channels using cloud targets (Withdrawal Notice)," Proc. SPIE 7859, Remote Sensing of the Atmosphere and Clouds III, 785902 (28 October 2010); doi: 10.1117/12.869440

SPIE. Event: SPIE Asia-Pacific Remote Sensing, 2010, Incheon, Korea, Republic of 


\section{Assessment of the calibration performance of Meteosat-8/9 and MTSAT-1R visible channels using cloud targets (Withdrawal Notice)}

Proc. SPIE 7859, 785902 (2010); http://dx.doi.org/10.1117/12.869440

Online Publication Date: 28 October 2010

Retracted from Publication: 10 January 2011

Conference Date: Tuesday 12 October 2010

Conference Location: Incheon, Republic of Korea

Conference Title: Remote Sensing of the Atmosphere and Clouds III

Conference Chairs: Sonoyo Mukai, Robert J. Frouin, Byung-Ju Sohn

Byung-Ju Sohn and Seung-Hee Ham

Seoul National Univ. (Republic of Korea)

This paper was presented at the SPIE conference indicated above and has been withdrawn from publication at the request of the authors. 